\title{
Fibrinolysis in leukaemia
}

\author{
D. OGSTON, G. M. McANDREW, AND C. M. OGSTON
}

From the Department of Medicine, University of Aberdeen, and Aberdeen Royal Infirmary

SYNOPSIS Components of the blood fibrinolytic system were measured in 43 patients with leukaemia. Increased fibrinolytic activity, indicated by a reduced plasma plasminogen level, was found in 14 patients. The combination of severe thrombocytopenia and increased fibrinolysis appeared to be a determinant in the production of a haemorrhagic tendency in leukaemia.

A haemorrhagic tendency is a common feature of leukaemia, particularly acute leukaemia. Bleeding is usually due to thrombocytopenia, but a number of cases of a haemorrhagic state associated with abnormal fibrinolytic activity have been reported in leukaemia (Cooperberg and Neiman, 1955; Pisciotta and Schulz, 1955; Nilsson, Björkman, and Andersson, 1961; Brown, Campbell, and Thompson, 1962). We have studied the blood fibrinolytic enzyme system in patients with leukaemia to determine the frequency of pathological fibrinolytic activity, and its possible role in the haemorrhagic tendency.

Received for publication 30 June 1967.
PATIENTS AND METHODS

PATIENTS Forty-three patients, aged 17 to 91 years, were studied. The type of leukaemia was diagnosed by the peripheral blood smear appearances and, where necessary, by bone marrow examination. Thirteen patients had acute, myeloid leukaemia (including the Naegeli type of monocytic leukaemia); six had subacute or acute lymphatic leukaemia; five had the Schilling type of monocytic leukaemia; 11 had chronic lymphatic leukaemia; and eight had chronic myeloid leukaemia. All were studied before treatment or within 24 hours of the start of specific therapy and before blood replacement.

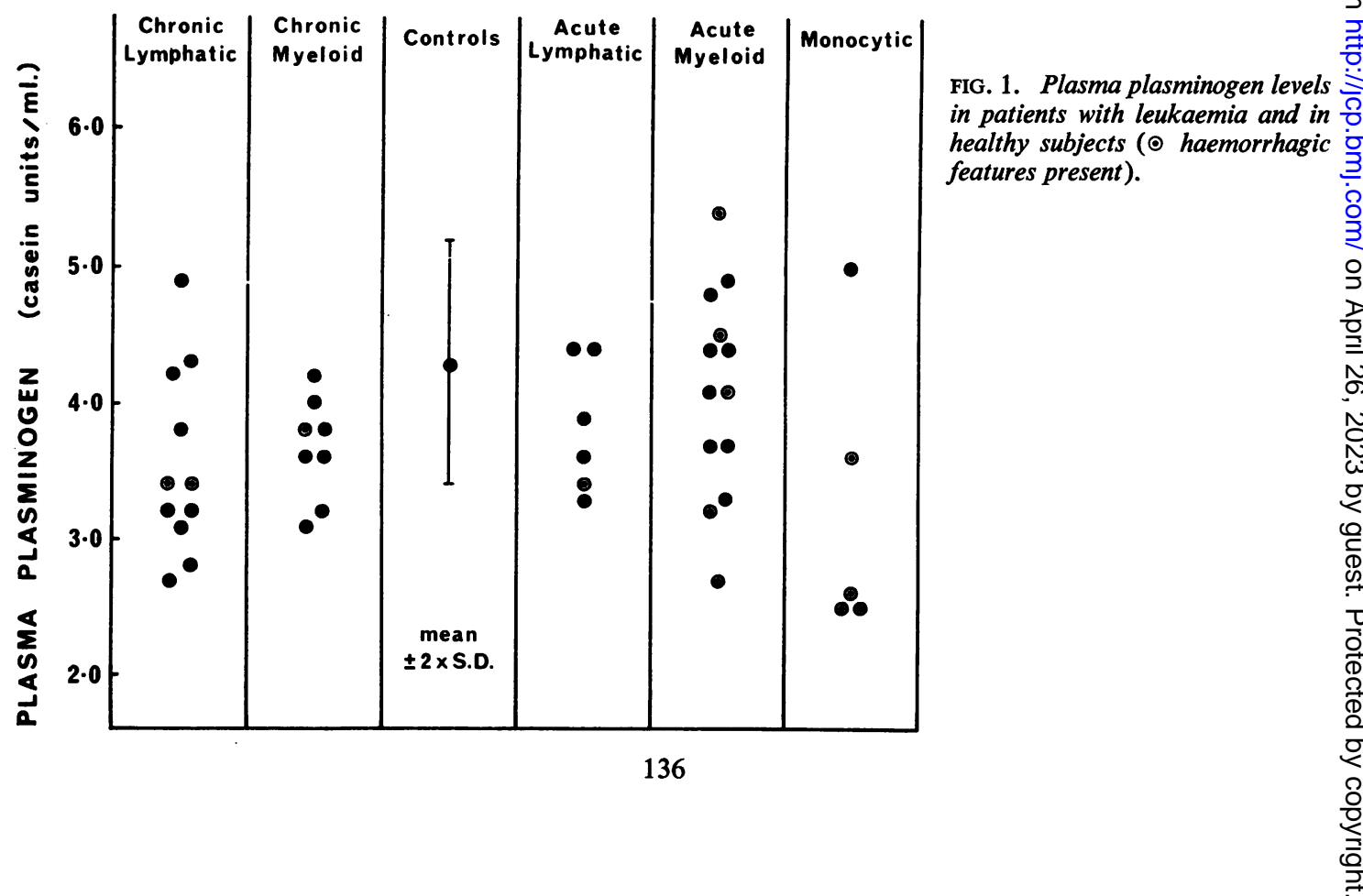


PLASMINOGEN ACtivator This was assessed by estimating euglobulin clot lysis times by the method of Nilsson and Olow (1962), and the results were expressed by plotting the values logarithmically against units of fibrinolytic activity (Sherry, Lindemeyer, Fletcher, and Alkjaersig, 1959), 10 units being arbitrarily equated with a lysis time of 50 minutes. Times over 500 minutes were designated as less than 1 unit. A range of 1.1 to 10.0 units (mean 4.5 , SD 1.9) was found in 35 patients convalescent from minor disorders.

PLASMA PLASMINOGEN This was estimated by the caseinolytic method of Remmert and Cohen (1949) as modified by Alkjaersig, Fletcher, and Sherry (1959), and the results are expressed in Sherry units. A range of 2.9 to 5.5 casein units (mean 4.3, SD 0.45) was found in 178 healthy subjects aged 16 to 65 years (Ogston and Ogston, 1966).

PLASMA FIBRINOGEN Fibrinogen was estimated by a modification (Ogston and Ogston, 1966) of the method of Ratnoff and Menzie (1951). Plasma fibrinogen levels rise with age; each patient's fibrinogen concentration has, therefore, been compared with the level for normal subjects in the same age group (Ogston and Ogston, 1966).

\section{RESULTS}

PLASMA PLASMINOGEN The plasma plasminogen concentration was measured in all 43 patients. The individual values for the patients subdivided according to the type of leukaemia are shown in Figure 1. Fourteen patients had a plasma plasminogen level more than 2 SD below the mean of the control subjects, and these low levels were not related to the type of leukaemia.

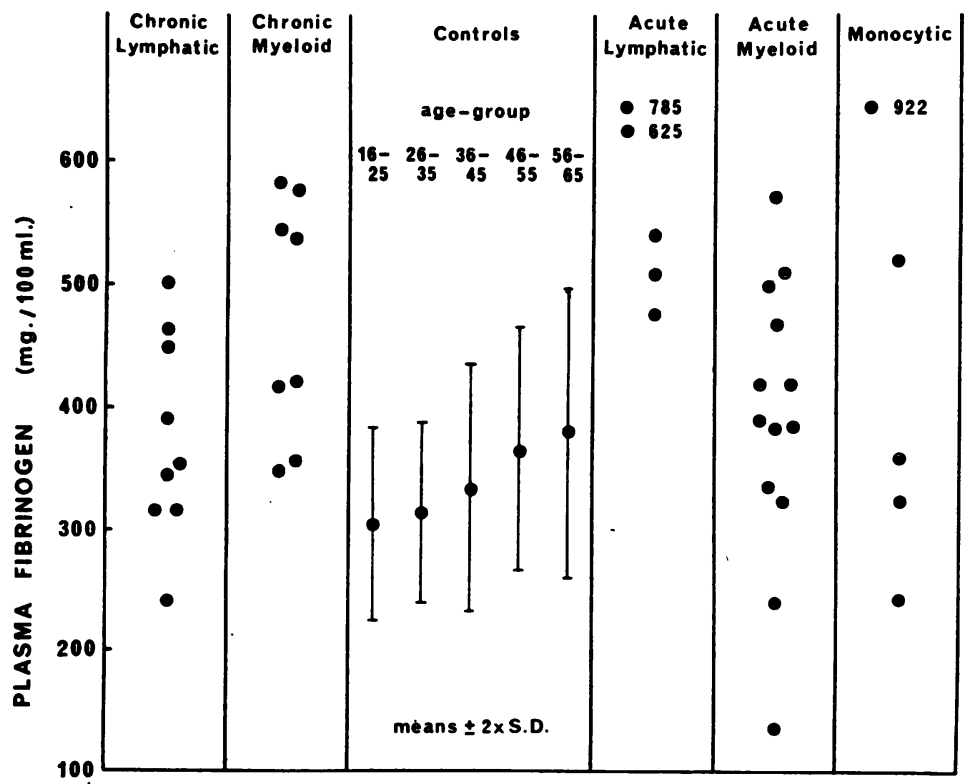

PLASMA FIBRINOGEN The plasma fibrinogen level was estimated in $\mathbf{4 0}$ patients. Four patients had a plasma fibrinogen level more than 2 SD below the mean for healthy subjects in the same age group while 14 patients had a level more than 2 SD above the mean for control subjects (Fig. 2). Three of the patients with a reduced plasma fibrinogen level had a plasma plasminogen concentration under 3 casein units/ml.

PLASMA PLASMINOGEN ACTIVATOR Euglobulin clot lysis times were performed in 37 patients, and there was a wide scatter of results (Fig. 3) with high levels in three patients and low levels in seven patients. Two of the three patients with increased plasminogen activator had low plasminogen levels; five of the seven patients with decreased activator had a plasma fibrinogen of over $500 \mathrm{mg} / 100 \mathrm{ml}$.

RELATIONSHIP BETWEEN COMPONENTS OF THE FIBRINOLYTIC SYSTEM, THROMBOCYTOPENIA, AND HAEMORRHAGIC FEATURES Thirteen patients had haemorrhagic features at the time of study. Table I shows the relationship between the presence of haemorrhagic features, marked thrombocytopenia, and plasminogen level; the individual plasminogen levels in the presence or absence of a bleeding tendency are shown in Figure 1. Eight of the 11 patients with severe thrombocytopenia (under $40,000 / \mathrm{cmm}$ ) and a bleeding tendency had also a low plasminogen level whereas the plasminogen was normal in the three patients with thrombocytopenia who did not have a bleeding

FIG. 2. Plasma fibrinogen levels in patients with leukaemia and in healthy subjects divided into age groups $(\odot$ haemorrhagic features present). 


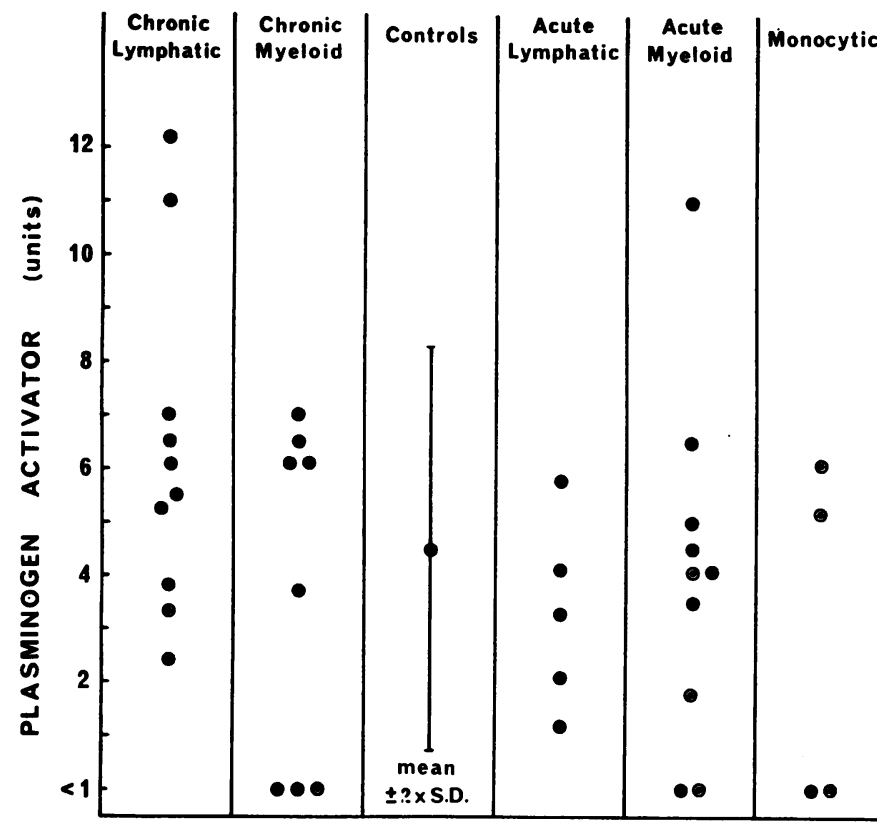

FIG. 3. Plasminogen activator levels in patients with leukaemia and in control subjects (॰ haemorrhagic features present).

TABLE I

RELATIONSHIP BETWEEN HAEMORRHAGIC FEATURES, SEVERE THROMBOCYTOPENIA, AND PLASMINOGEN LEVEL IN LEUKAEMIC PATIENTS

\begin{tabular}{|c|c|c|c|c|c|c|}
\hline \multirow{2}{*}{$\begin{array}{l}\text { Haemorrhagic } \\
\text { Features }\end{array}$} & \multirow{2}{*}{$\begin{array}{l}\text { Platelet } \\
\text { Count } \\
(\text { per } \mathrm{cmm})\end{array}$} & \multirow[t]{2}{*}{ No. } & \multicolumn{4}{|c|}{$\begin{array}{c}\text { No. with Plasminogen Level } \\
\text { (casein units } / m l)\end{array}$} \\
\hline & & & $>4$ & $3 \cdot 6-4 \cdot 0$ & $3 \cdot 0-3 \cdot 5$ & $<3$ \\
\hline Present & $\begin{array}{l}\text { Under } 40,000 \\
\text { Over } 40,000\end{array}$ & $\begin{array}{lr}0 & 11 \\
0 & 2\end{array}$ & $\stackrel{3}{-}$ & $\overline{2}$ & $\underline{4}$ & $\stackrel{4}{-}$ \\
\hline Absent & $\begin{array}{l}\text { Under } \mathbf{4 0 , 0 0 0} \\
\text { Over } \mathbf{4 0 , 0 0 0}\end{array}$ & $\begin{array}{rr}0 & 3 \\
0 & 27\end{array}$ & $\begin{array}{r}2 \\
10\end{array}$ & $\begin{array}{l}1 \\
8\end{array}$ & $\overline{7}$ & $\overline{2}$ \\
\hline
\end{tabular}

tendency. A low plasminogen level in the absence of severe thrombocytopenia was not associated with a haemorrhagic tendency.

The plasma fibrinogen levels bore no relation to haemorrhagic features except that three of the four patients with a significantly decreased fibrinogen level had a bleeding tendency.

None of the patients with an increased plasminogen activator level had evidence of abnormal bleeding.

RELA IIONSHIP OF LIVER FUNCTION TO CHANGES IN THE COMPONENTS OF THE FIBRINOLYTIC SYSTEM Liver function was assessed by estimating the serum bilirubin, alkaline phosphatase, aspartate transaminase, and the serum protein fractions in 23 of the patients with leukaemia, including seven with a lowered plasminogen level. Apart from alterations in the serum protein pattern such as hypogammaglobulinaemia the values lay within the normal range. It was concluded that reduced plasminogen levels in patients with leukaemia were not the result of hepatic dysfunction.

\section{DISCUSSION}

Pathological fibrinolytic states are due to the rapid conversion of plasminogen to plasmin in excess of the normal protective effect of antiplasmins. The resulting proteolytic activity results in the destruction of fibrinogen and a number of clotting factors and, in addition, the split products of fibrinogenolysis interfere with normal fibrin polymerization. A severe haemorrhagic state may ensue, but in milder cases there may only be purpuric features(Sherry, Fletcher, $N$ and Alkjaersig, 1959). Such conversion of plasminogen to plasmin secondary to the release of plasmino- N gen activator is frequently transient and it may not be possible to demonstrate increased quantities of $\bar{O}$ activator or plasmin in the blood. The plasminogen 0

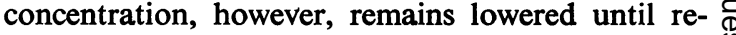
synthesis is complete and lowered fibrinogen levels may also be found.

In addition to excessive utilization lowered plasma plasminogen levels may result from impaired synthe- $\frac{\mathbb{Q}}{8}$ sis. Although the site of plasminogen production is $\mathbb{D}$ not yet established it is likely that, in common with 
other globulins, the liver is the principal site. Impaired synthesis has not yet been conclusively proved to be a cause of hypoplasminogenaemia although we have suggested such a mechanism as the cause in some cases of Hodgkin's disease (McAndrew and Ogston, 1965). In the absence of liver disease, therefore, lowered blood plasminogen levels may be taken to indicate excessive utilization of plasminogen by the action of plasminogen activator and therefore as evidence of pathologically increased fibrinolytic activity. In this study we have found 14 of the 43 patients with leukaemia studied to have abnormally low plasma plasminogen levels.

Depression of the plasma fibrinogen level may be due to destruction by proteolytic enzymes such as plasmin, to impaired synthesis, or to excessive utilization through its conversion to fibrin. This last mechanism was considered to be the main factor in producing hypofibrinogenaemia in the four patients with leukaemia described by Hirsh, Buchanan, de Gruchy, and Baikie (1967). In this study four patients with leukaemia had an appreciably reduced plasma fibrinogen level. Three of these patients had also a low plasminogen level; in the absence of evidence of hepatic dysfunction it is reasonable to suppose that pathologically increased fibrinolytic activity was the cause of the hypofibrinogenaemia. Raised fibrinogen levels have been reported in leukaemia (Welsh, Robinson, and Bird, 1961); it is likely that these are related principally to the increased tendency to infections in leukaemia.

The relationship between the presence of a haemorrhagic tendency, severe thrombocytopenia, and lowered plasminogen levels suggests that even a minor increase in plasma proteolytic activity, when associated with thrombocytopenia, may result in a haemorrhagic state. This may partly explain the dis- sociation sometimes noted between thrombocytopenia and the occurrence of bleeding in patients with leukaemia.

The findings of this study suggest that, although haemorrhagic features in patients with leukaemia are not commonly the result of abnormal fibrinolytic activity alone, a considerable proportion of patients with such features have evidence of excessive fibrinolysis which, in combination with thrombocytopenia, may induce a haemorrhagic state. A practical application of this observation is that even in patients in whom bleeding appears to be due to thrombocytopenia, a trial of an inhibitor of fibrinolysis, for example, epsilon amino-caproic acid, may be of value in the control of haemorrhage.

We thank Professor H. W. Fullerton for his advice in the preparation of this paper, and the physicians of the Aberdeen General Hospitals for permission to study patients under their care.

\section{REFERENCES}

Alkjaersig, N., Fletcher, A. P., and Sherry, S. (1959). J. clin. Invest., 38, 1086.

Brown, R. C., Campbell, D. C., and Thompson, J. H. (1962). Arch. intern. Med., 109, 210.

Cooperberg, A. A., and Neiman, G. M. A. (1955). Ann. intern. med., 42, 706.

Hirsh, J., Buchanan, J. G., de Gruchy, G. C., and Baikie, A. G. (1967). Lancet, 1, 418.

McAndrew, G. M., and Ogston, D. (1965). Scot. med. J., 10, 241.

Nilsson, I. M., Björkman, S. E., and Andersson, L. (1961). Acta med. scand., 170, 487.

-, and Olow, B. (1962), Acta chir. scand., 123, 247.

Ogston, C. M., and Ogston, D. (1966). J. clin. Path., 19, 352.

Pisciotta, A. V., and Schulz, E. J. (1955). Amer. J. Med., 19, 824.

Ratnoff, O. D., and Menzie, C. (1951). J. Lab. clin. Med., 37, 316.

Remmert, L. F., and Cohen, P. P. (1949). J. biol. Chem., 181, 431.

Sherry, S., Fletcher, A. P., and Alkjaersig, N. (1959). Physiol. Rev., 39, 343.

Lindemeyer, R. I., Fletcher, A. P., and Alkjaersig, N. (1959). J. clin. Invest., 38,810 .

Welsh, J. D., Robinson, C., and Bird, R. M. (1961). Amer. J. med. Sci., 241, 207. 